\title{
Serum urea analysis using the Beckman BUN Analyzer
}

\author{
K. S. CHUA AND I. K. TAN \\ From the Clinical Biochemistry Laboratories, Department of Pathology, Outram Road, Singapore
}

SYNOPSIS A new instrument, the Beckman BUN Analyzer, has been produced for the estimation of urea in microvolume $(0.01 \mathrm{ml})$ of serum or plasma. It requires only a simple two-point calibration for standardization and is suitable for a range of urea levels from zero to $70 \mathrm{mmol} / \mathrm{l}$. The test procedure is simple. After the initial calibration the test sample is injected into the testing chamber and a digital result of the urea concentration is displayed. Serum urea measurements made by this method compared well with those obtained by the Technicon AutoAnalyzer method over the entire working range. The within-batch coefficient of variation of the method is $5.5 \%$, and less at urea levels of 11 to $44 \mathrm{mmol} / \mathrm{l}$. The between-batch coefficient of variation of the method is $6.9 \%$, and less at urea concentrations of 10 to $47 \mathrm{mmol} / \mathrm{l}$. The BUN Analyzer method is a quick and reliable alternative to conventional laboratory methods for serum or plasma urea estimation and is especially useful for urgent investigations of both adult and paediatric patients in the hospital wards and at the outpatient clinics.

The introduction of the Beckman BUN Analyzer, which gives a direct digital display of urea nitrogen result upon injection of test sample into the reagentsample chamber of the instrument, was a valuable advance in the technology of urea measurements. As the instrument requires only $0.01 \mathrm{ml}$ serum and the entire test procedure can be completed within 2 minutes with the instrument in the standby mode, the method is particularly useful for emergency investigations of paediatric patients. Pretreatment of serum/ plasma specimens such as protein precipitation is not required. A study was carried out to assess the reproducibility and accuracy of the instrument as well as to evaluate the urea reagents prepared by our laboratory versus that supplied by the manufacturer of the instrument. This paper presents and discusses the results of these investigations.

\section{Material and Methods}

UREA STANDARDS FOR CALIBRATION

(A) Aqueous urea nitrogen standard solution of $18 \mathrm{mmol} / \mathrm{l}$ provided by the manufacturer (Beckman Certified Standard)

(B) Technicon freeze-dried standard serum for calibration of the SMA 6 Plus multichannel analyser.
SERA

Sera from hospital patients received by the laboratory for routine urea and electrolytes determinations were used for the reproducibility and comparative studies.

UREA-REAGENTS（A)

These were reagents supplied by the manufacturers: (1) Tris buffer of $250 \mathrm{ml}$ consisting of Tris-(hydroxymethyl) aminoethane, the disodium salt of EDTA and N-2-hydroxyethyl-piperazine- $\mathrm{N}^{\prime}$-2-ethanesulphonic acid, with butylparaben added as preservative (concentrations of individual constituents were not stated)

(2) Lyophilized urease powder stored in a small glass vial

(3) Working buffered-urease reagent prepared on the day of analyses by dissolving (2) completely in (1). Sufficient reagent for the estimated number of tests to be performed in a batch was transferred into the bottle in the $37^{\circ} \mathrm{C}$ chamber of the instrument. The remaining reagent was stored in the refrigerator for subsequent use for a period of up to a week.

UREA-REAGENTS (B)

These were reagents prepared by the authors:

(1) Tris buffer, $0.05 \mathrm{M}, \mathrm{pH} 7.6$ containing $1 \mathrm{~g} / 1$ of the disodium salt of EDTA. This was prepared by 
mixing Tris base $(0.6055 \mathrm{~g} / 100 \mathrm{ml})$ and Tris- $\mathrm{HCl}$ $(0.7875 \mathrm{~g} / 100 \mathrm{ml})$ in the proportion of $1.3: 1.0$ and adding $100 \mathrm{mg}$ of EDTA disodium salt to every 100 $\mathrm{ml}$ of the mixture

(2) Urease powder type III obtained from Sigma Chemical Co Ltd. This had urease activity of 3900 units $/ g$, one unit of urease activity being defined as that which produced $1 \mathrm{mg}$ ammonia nitrogen from urea in 5 minutes at $\mathrm{pH} 7.0$ at $30^{\circ}$

(3) Working buffered-urease reagent prepared on the day of analyses by prediluting (1) 50 times with distilled water to bring the concentration to $0.001 \mathrm{M}$ and adding (2) to give a concentration of $70 \mathrm{mg}$ urease per $100 \mathrm{ml}$ solution. Although no preservative was added to the buffer, it was found that the buffered-urease reagent thus prepared could be stored for a minimum of three days at $4^{\circ} \mathrm{C}$.

\section{PRINCIPLE OF ANALYSIS}

On injection of a precise volume of test sample into a magnetically stirred cup containing a defined volume of buffered-urease reagent the urease in the reagent acts upon urea, a non-ionic compound, in the test sample to produce ammonium and bicarbonate ions. The conductivity electrode immersed in the solution measures the change in conductivity and the solidstate circuitry converts this signal to a rate function. As the rate of the reaction is directly proportional to the concentration of the reactants, the rate of ammonium carbonate formation is proportional to the urea concentration in the sample. The analyser measures the rate during a fixed period of time and permits scaling of results to provide a direct, digital meter readout in milligrams urea nitrogen per 100 $\mathrm{ml}$. However, in the present paper all results have been converted to SI units of millimoles per litre.

\section{PROCEDURE OF ANALYSIS}

The directions given in the operating manual for the BUN Analyzer (Beckman Instruments, Inc) were followed precisely. For samples with urea levels above $36 \mathrm{mmol} / \mathrm{l}$, the buffered-urease reagent was doubled as recommended and results were multiplied by 2 .

For the comparative study, urea concentrations on 135 serum samples were measured by both the BUN Analyzer and the Technicon SMA 6 Plus system (Technicon Equipment Pty Ltd).

\section{Results and Discussion}

\section{REPRODUCIBILITY OF THE METHOD}

Ten replicate analyses on each of three serum samples with different urea levels were performed using urea-reagent A3. The aqueous urea standard was used for the standardization of the instrument.
The within-batch coefficients of variation of the method were $5.5 \%(\mathrm{SD}=0.60)$ at a urea concentration of $11.0 \mathrm{mmol} / \mathrm{l}, 3.1 \%(\mathrm{SD}=0.73)$ at 23.2 $\mathrm{mmol} / \mathrm{l}$, and $1.7 \%(\mathrm{SD}=0.73)$ at $44.2 \mathrm{mmol} / \mathrm{l}$.

For the evaluation of between-batch reproducibility, daily estimation of urea was made on three pooled sera over a period of one month. The between-batch coefficient of variation was $6.9 \%$ $(\mathrm{SD}=0.71)$ at a urea concentration of $10.3 \mathrm{mmol} / \mathrm{l}$, $5.1 \%(\mathrm{SD}=1.26)$ at $24.6 \mathrm{mmol} / 1$, and $1.3 \%(\mathrm{SD}=$ 0.61 ) at $47 \cdot 2 \mathrm{mmol} / \mathrm{l}$.

COMPARATIVE STUDY

A total of 76 serum samples with the urea concentration varying between 1.8 and $53.6 \mathrm{mmol} / 1$ were assayed by the BUN Analyzer using urea-reagent A3 and by the Technicon SMA 6 Plus multichannel analyser. For this comparative study, Technicon freeze-dried reference serum standard was used for the calibration of both instruments. A correlation coefficient of 0.995 was obtained (figure).

EFFECT OF OXALATE AND EDTA

Because blood specimens containing oxalate or EDTA as anticoagulants were occasionally received by the routine laboratory for urea determination, the effect of these anticoagulants on the BUN Analyzer method was investigated. The results given in the table show that there was no significant interference by either anticoagulant when present in the quantity used for obtaining plasma from whole

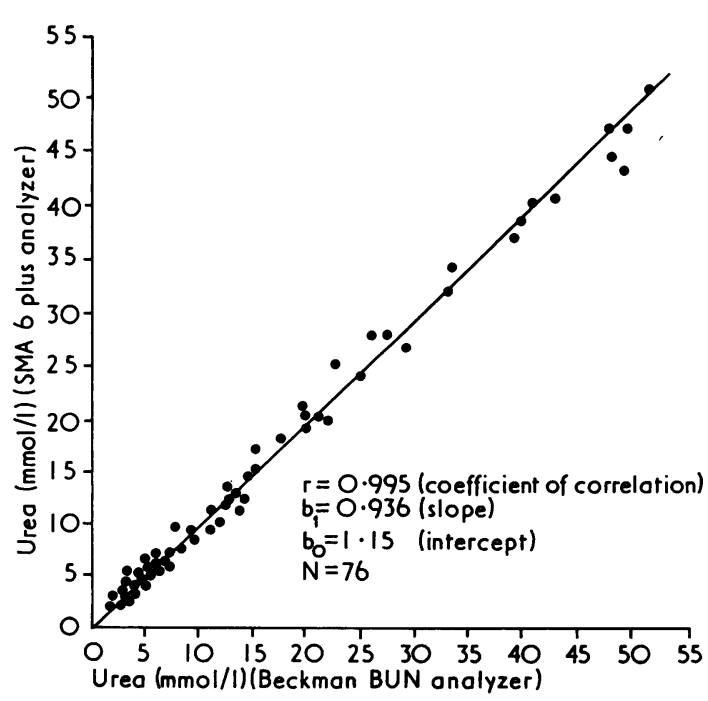

Figure Comparison of Beckman BUN Analyzer and SMA 6 Plus method using Beckman's reagents. 


\begin{tabular}{|c|c|c|}
\hline \multirow{2}{*}{ Sample } & \multicolumn{2}{|c|}{ Urea $(\mathrm{mmol} / \mathrm{l})$} \\
\hline & $\begin{array}{l}\text { BUN } \\
\text { Analyzer }\end{array}$ & $\begin{array}{l}\text { SMA } 6 \text { Plus } \\
\text { Analyser }\end{array}$ \\
\hline \multicolumn{3}{|c|}{ Plasma (oxalate) } \\
\hline 1 & $2 \cdot 9$ & 3.7 \\
\hline 2 & $4 \cdot 0$ & $3 \cdot 7$ \\
\hline 3 & $4 \cdot 2$ & $4 \cdot 5$ \\
\hline 4 & 4.9 & $5 \cdot 3$ \\
\hline 5 & $8 \cdot 4$ & 6.9 \\
\hline 6 & $10 \cdot 3$ & $9 \cdot 4$ \\
\hline 7 & $10 \cdot 6$ & $10 \cdot 2$ \\
\hline 8 & $12 \cdot 7$ & $12 \cdot 1$ \\
\hline 9 & $17 \cdot 6$ & $17 \cdot 9$ \\
\hline 10 & $18 \cdot 2$ & $19 \cdot 1$ \\
\hline 11 & $22 \cdot 1$ & $20 \cdot 7$ \\
\hline 12 & $22 \cdot 9$ & $22 \cdot 7$ \\
\hline 13 & $25 \cdot 7$ & $24 \cdot 1$ \\
\hline 14 & $30 \cdot 3$ & $29 \cdot 4$ \\
\hline 15 & $39 \cdot 6$ & $40 \cdot 1$ \\
\hline \multicolumn{3}{|c|}{ Plasma (EDTA) } \\
\hline 1 & $2 \cdot 3$ & $2 \cdot 2$ \\
\hline 2 & $2 \cdot 4$ & 3.0 \\
\hline 3 & $3 \cdot 1$ & $3 \cdot 3$ \\
\hline 4 & $3 \cdot 4$ & $3 \cdot 0$ \\
\hline 5 & $4 \cdot 8$ & $4 \cdot 8$ \\
\hline 6 & $9 \cdot 0$ & $9 \cdot 3$ \\
\hline 7 & 10.9 & 9.9 \\
\hline 8 & $14 \cdot 8$ & $13 \cdot 8$ \\
\hline 9 & $20 \cdot 4$ & $19 \cdot 2$ \\
\hline 10 & $23 \cdot 1$ & $21 \cdot 5$ \\
\hline 11 & 23.9 & $24 \cdot 0$ \\
\hline 12 & $26 \cdot 1$ & $25 \cdot 0$ \\
\hline 13 & $33 \cdot 0$ & $31 \cdot 2$ \\
\hline 14 & $38 \cdot 0$ & 37.0 \\
\hline 15 & $50 \cdot 4$ & $49 \cdot 0$ \\
\hline
\end{tabular}

Table Effect of oxalate and EDTA

blood ( $2 \mathrm{mg}$ oxalate/ml blood and $1 \mathrm{mg}$ EDTA/ml blood).

STUDIES USING UREA-REAGENT B 3

When the above studies were repeated using ureareagent B3, which was prepared by the authors, similar results were obtained, indicating that there was no significant difference in the quality of performance when either reagent A3 or B3 was used.

\section{Conclusion}

In our experience, serum urea nitrogen analyses using the Beckman BUN Analyzer compared well with analyses performed on the Technicon SMA 6 Plus. The instrument gave good precision for routine operation. The simplicity of the procedure, the need for only microvolumes of test sample, the use of one single reagent, and the speed with which an assay can be completed all contribute to the desirability of the instrument in a routine laboratory for outpatients or an emergency laboratory for hospital inpatients. It can be used to supplement multichannel analysers which are already in use in a number of laboratories. In this case it can be used exclusively for urgent measurements and for repeating determinations on samples with results which are above-scale on the multichannel analyser.

By the use of the urea-reagent prepared by the authors and assessed in this study it was possible to reduce routine running costs to approximately onefourth of that incurred when the manufacturer's reagents were used. The omission of N-2-hydroxyethyl-piperazine-N-2-ethanesulphonic acid and butylparaben, which were included in Beckman's reagents, did not adversely affect the analyses.

With the increasing use of SI units in hospital laboratories, it is suggested that the manufacturer provides for the automatic conversion of the digital readout from milligrams urea nitrogen per $100 \mathrm{ml}$ to millimoles urea per litre.

We wish to thank Mr T. C. Goh for supplying data for the day-to-day precision of the BUN Analyzer during routine operation and to Mrs T. H. Koh for typing the script.

\section{References}

Beckman BUN Analyzer Operation Manual (015-083589-A) Technicon SMA 6 Plus Operation Manual 